\title{
THE AGEING OF CARDIAC INFARCTS, AND ITS INFLUENCE ON CARDIAC RUPTURE
}

\author{
BY \\ IAN LODGE-PATCH
}

From the Bernhard Baron Institute of Pathology, the London Hospital

Received December 23, 1949

In about 9 per cent of necropsies upon cases of fatal recent cardiac infarction hæmopericardium is found as a complication (Edmondson and Hoxie, 1942; Diaz-Rivera and Miller, 1948; Friedman and White, 1944). Rupture of the heart is practically confined to the first three weeks after infarction although it occasionally occurs at later stages with cardiac aneurysm. Death is not usually immediate upon rupture, but follows at an interval of several hours, being probably due to circulatory failure caused by cardiac tamponade. Rupture occurs less frequently when cardiac infarction has been recognized, and the patient is at rest in hospital; more often, and in at least five of our nine cases, the catastrophe has occurred in an imperfectly treated patient arriving at hospital either moribund or dead. In this connection it is of interest that Jetter and White (1944) found that rupture of recent cardiac infarcts occurred in no fewer than 73 per cent of a small series (27) of patients in mental institutions; they had made no complaint of pain and therefore had not been treated. In the absence of clinical evidence the authors estimated the age of the infarcts by the histological criteria of Mallory et al. (1939). Such criteria may thus assume medico-legal importance in the absence of a clear history of the onset of infarction, since microscopical examination may be the only method of estimating the age of the lesion.

The purpose of this report is to re-examine the sequence of histological changes in the myocardium in recent infarction, and to estimate accordingly the period at which hæmopericardium is likely to supervene.

From a total of 216 cases of recent infarction that came to necropsy in this Institute a series of 18 cases uncomplicated by rupture was selected on the strength of a clear history of the onset being available, together with adequate histological preparations. The cases provided material dating from one day onwards, with the exception of the third day, when no representative sections were available. The results of this study were then compared with those of Mallory et al. (1939).

Nineteen of the 216 cases $(8.8 \%)$ were complicated by hæmopericardium. Of these 10 were discarded on account either of the inadequacy of the histological preparations, or from the presence of some complicating factor such as syphilitic aortitis or polyarteritis nodosa. The period at which rupture occurred was estimated, in the remainder, on the basis of the histological criteria acquired from study of the uncomplicated 18 cases.

\section{Stages of Healing of Cardiac Infarcts}

Macroscopic appearances. About 15 hours after coronary thrombosis the infarct is usually pale, swollen and odematous. This appearance becomes more marked until, at about 36 hours, it begins to acquire a hæmorrhagic border. The central part of such an infarct appears obviously dead, being opaque and yellowish or yellowish-grey.

On succeeding days the clarity of definition of the infarct increases; by about the middle of the first week its centre is of rubbery consistency and the hæmorrhagic border is most distinct, although 
not always present. Towards the end of the first week the infarct sometimes appears slightly shrunken; the area of central necrosis may become softened and grey. Irregularity of the infarct, or of the plane of section, may give an appearance of mottling with red, rather than distinct zones of grey and red. Obvious thinning of the infarcted myocardium occurs after about three weeks.

Before scarring becomes evident at 6 to 8 weeks, the infarct often appears brownish. By three months the tissue on section is white and firm, although vascularized granulation tissue is still recognizable. Tough white fibrous tissue is the final product of a healed infarct.

Microscopical appearance. The character of the cellular exudate is the most valuable feature in estimating the age of a young infarct and data about the time these changes are found are shown in Fig. 1.

6 HOURS. 24 HOURS. 48 HOURS 3-5 DAYS. 7-10 DAYS. 14-21 DAYS. 6 WEEKS. YEARS.

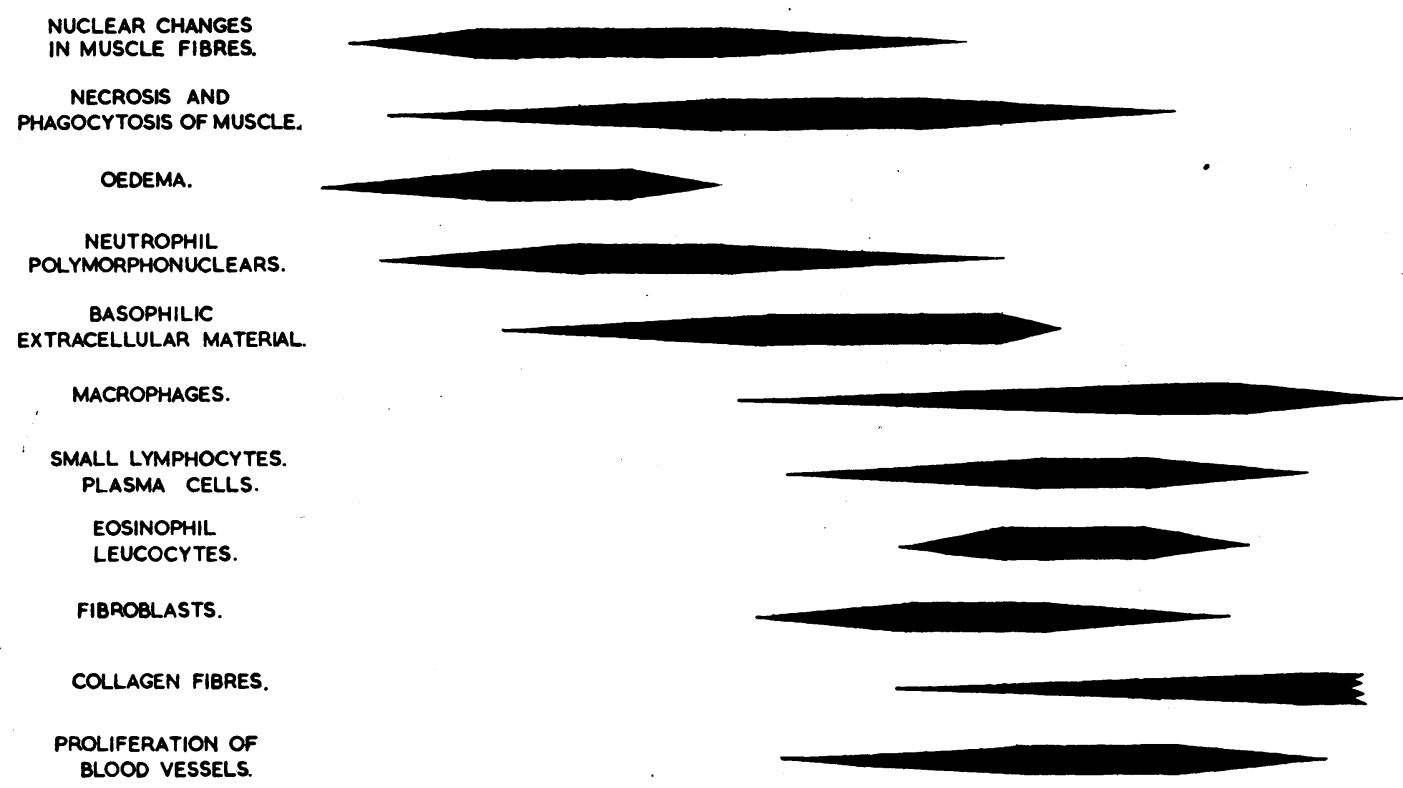

FIG. 1 The character of the cellular exudate at various stages after cardiac infarction.

Neutrophil polymorphonuclear leucocytes are the typical cells of the earliest stages. They appear at about six hours after cardiac infarction, increase in number rapidly after. 24 hours, and at $\mathbf{4 8}$ hours are massed on the periphery of the infarcted area, penetrating between the dead muscle fasciculi for a short distance (Fig. 2). These cells are most numerous from the third to the fifth days. At 48 hours necrotic changes appear in individual leucocytes. Pyknotic nuclear remnants become increasingly abundant at successive stages, and an extracellular basophilic material, probably derived from the disrupted leucocytes, appears in increasing quantities around the necrotic muscle. This, combined with odema-one of the earliest features-separates the muscle fasciculi, alive or dead. The basophilic material is most prominent between the fourth and tenth days and with the cellular leucocytic debris has disappeared towards the end of the second week, although sometimes persisting centrally within a large infarct for longer periods.

By the fourth day large mononuclear macrophages are present in places at the outer borders of the infarct, peripheral to the degenerating leucocytes. They increase to a maximum at the end of the sixth week, subsequently declining gradually, although present for as long as two or more years. These macrophages phagocytose fragments of the necrotic muscle, ingest pigment from the destroyed muscle cells, and become swollen, golden-yellow and granular. This pigment is present within the macrophages by the ninth day. Others appear foamy. 
Small lymphocytes appear at the periphery of the infarct at the fourth day but are scanty; they are present in greater numbers, and accompanied by plasma cells, at about the seventh day and increase to a maximum towards the end of three weeks; they then diminish in number, although they may persist after many months.

A few eosinophil leucocytes appear at the seventh to eighth day and increase rapidly in number

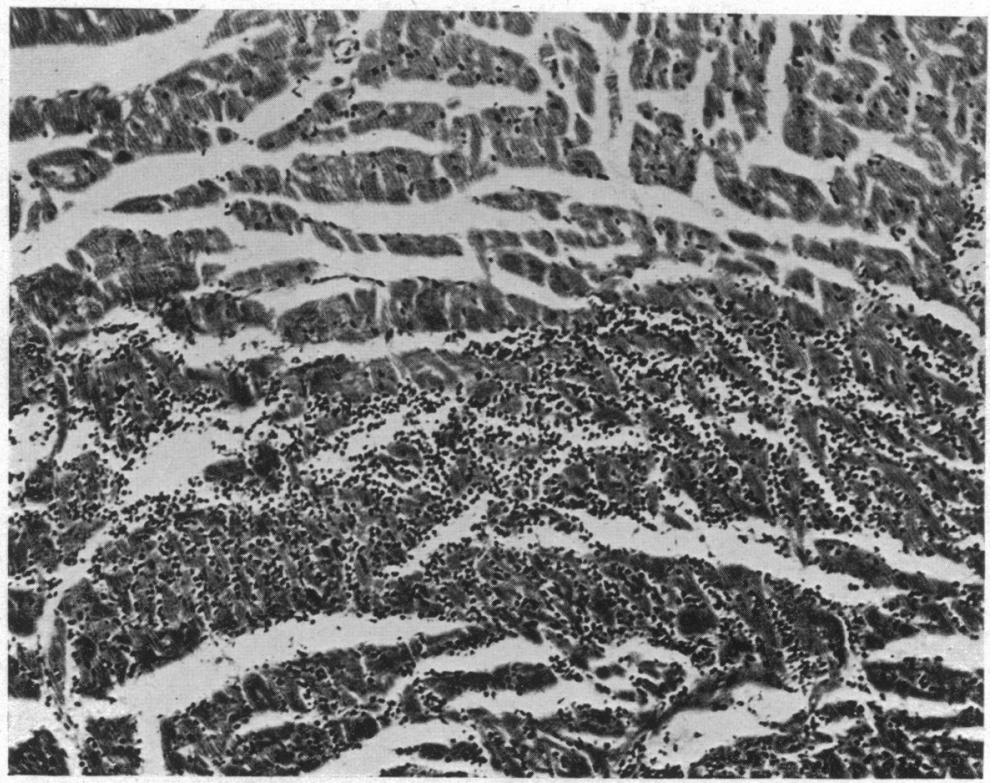

Fio. 2.-Border of infarct at $\mathbf{4 0}$ hours showing zone of neutrophil leucocytes; necrotic muscle above. Hæmatoxylin and eosin. Magnification, $\times 103$.

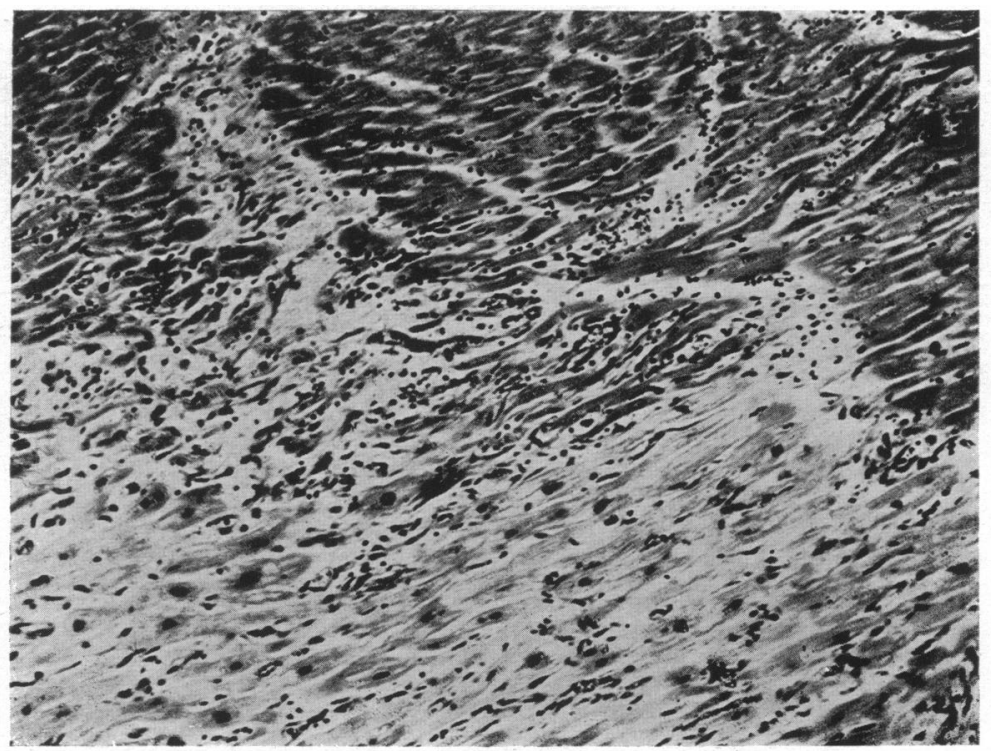

Fig. 3.-Border of infarct at 4 days showing young granulation tissue; necrotic muscle above. Hæmatoxylin and eosin. Magnification, $\times 95$. 
till about the twelfth day. When abundant they are characteristic of the third week, and are usually much fewer by the beginning of the fourth. They are not, however, a reliable indication of the age of an infarct since they may appear earlier or persist longer than the times mentioned, and may indeed be absent when their presence is most expected.

Fibroblasts are present in places by the fourth day, proliferating around the periphery of the infarcted muscle. They appear first, as part of a young granulation tissue, where the infarct approaches the endocardium or pericardium (Fig 3). At an early stage their cytoplasm is basophilic, but later this characteristic is lost. Collagen fibrils appear first about the ninth day, and the spindle fibroblasts, numerous at this period (Fig. 4), later become fewer and smaller; their nuclei

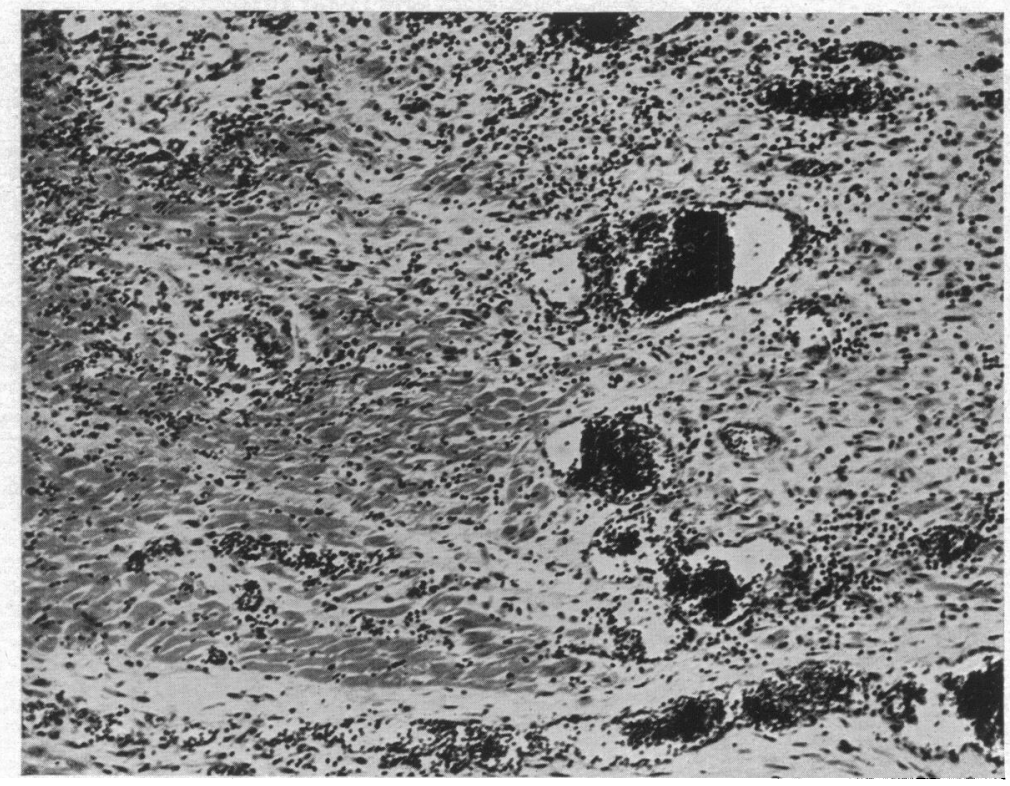

FIG. 4.-Organizing granulation tissue, rich in spindle fibroblasts and dilated capillaries, invading border of infarct at 10 days. Hæmatoxylin and eosin. Magnification, $\times 97$.

become smaller and more elongated after the third or fourth week. In the early stage of healing these cells are arranged irregularly, but after from two to three weeks their long axes become arranged parallel to the adjacent muscle fibres and visceral pericardium (Fig. 5).

Proliferating capillaries sprout into the infarct from its periphery and often give rise to small extravasations of red corpuscles. Thin-walled, and at first closely packed, they appear in the middle of the first week, the earliest indications of proliferation being present on the fourth day (Fig. 3). These new vessels are most abundant from 3 to 6 weeks, and later become less numerous.

In the cardiac muscle the earliest sign of cellular degeneration is found in the nuclei, some of which become swollen and pale with a crenated nuclear membrane. This appearance was noted at 5 hours. Later the nuclei become fragmented and disappear by karyolysis; others undergo pyknosis. At about 6 to 12 hours after coronary thrombosis, the cytoplasm becomes " glassy," and the striations less prominent, although these may persist indefinitely. The cytoplasm appears increasingly hyaline and eosinophilous from coagulation necrosis and this, though often patchy, is most marked at about four to six days after thrombosis.

Phagocytosis of muscle-fibres by macrophages produces a clearly cut edge to the mass of necrotic muscle after about two weeks, but although the process continues steadily, necrotic muscle may persist for many months in a large infarct.

The results of microscopical examination have been presented in Fig. 1. 


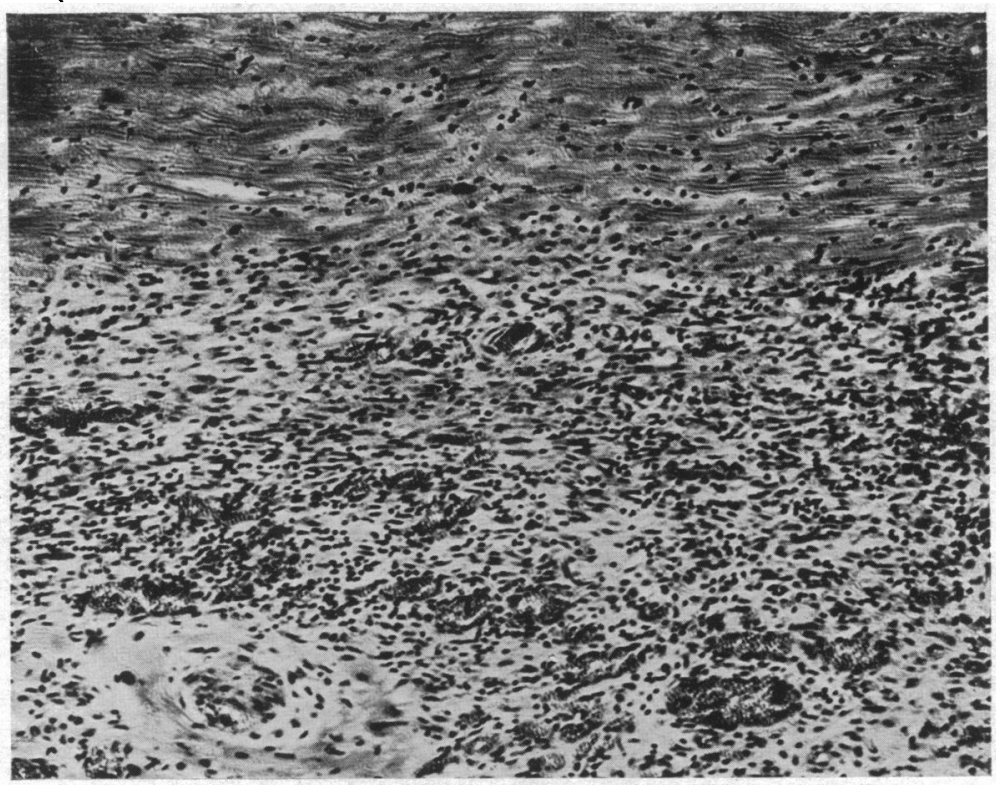

FIG. 5.-Border of infarct at 15 days showing cellular granulation tissue with many spindle fibroblasts parallel with necrosed muscle fibres. Hæmatoxylin and eosin. Magnification, $\times 105$.

\section{THE RUPTURED INFARCT}

Macroscopic appearances. In almost every case the infarct was described as pale, anæmic or yellowish, words that placed its probable age at 5 to 21 days. One described as " firm, opaque, pale and yellowish" was known from the clinical history to be not more than three and a half days old. In none of the cases of hæmopericardium had rupture occurred sufficiently long before death for organization of the pericardial clot to be distinguished at necropsy.

Microscopic appearances. Sections, in all these cases, included enough of the edge of the infarct to enable its age to be assessed in terms used in the larger series. In most cases blood had infiltrated in some degree between the fasciculi of the necrotic muscle surrounding the site of rupture, without obscuring the peripheral zone.

The age, estimated in this way, varied from about 10 to 14 days at the oldest, to about. 24 hours at the earliest. On histological grounds, the age of nine ruptured infarcts was estimated as follows: one of 1 day, two of $3 \frac{1}{2}$ to 5 days, two of 6 to 7 days, one of 7 to 8 days, two of 9 to 10 days, and one of 10 to 14 days.

Of these 9 cases, 5 had a clear clinical indication of the age of the infarct which agreed with the assessment made on histological examination.

\section{Discussion}

These observations on the stages of healing of infarcts and on their time-relationships agree with those of Mallory et al. (loc. cit.) except in a few details. Thus, no particular emphasis should be laid on the basophilia of fibroblasts which they regard as an important feature, because such a feature is common to rapidly proliferating cells. Again, for reasons that are given above, the appearance and development in conspicuous numbers of eosinophil leucocytes in the infiltration is an unreliable criterion of the age of an infarct. On the other hand, the orientation of fibroblasts is sometimes helpful for such assessment. The earliest changes found are intercellular and intracellular codema of the muscle-fibres, and their nuclear changes. 
The close agreement, in general, between my findings and those of Mallory and his co-workers suggests that infarcts of less than one week can be accurately dated to within 24 hours; in the second week, to within 36 to 48 hours, and up to 6 weeks old, within about 7 days. The corollary to this, namely the period during which rupture is likely to complicate infarction, is obviously of the greatest importance. . Few attempts have been made to assess this.

Isolated examples of hæmopericardium have been recorded since the first description by William Harvey but the first pathological analysis is that of Krumbhaar and Crowell in 1925. They described 22 cases-of spontaneous rupture and collected a further 632 that had been reported. Though histological examinations were made in most of their cases, the changes were not precisely related to the age of the infarct. In their monograph on the clinical features of coronary thrombosis Levine and Brown (1928) review 46 necropsies including 9 cases of hæmopericardium. These authors were the first to cite histological changes as an index of the age of the lesion, but their observations were general in character. They concluded that necrosis predominates from the fourth day to the end of the third week, that repair by collagen can be demonstrated on the sixth to seventh day but is not striking till the third week, that cicatrization sufficient to prevent rupture may be present by five weeks, and that firm scar-tissue may be observed eight weeks after the onsèt.

In the series of Mallory et al. (1939) there were eight examples of cardiac rupture. They calculated that this usually occurred within the first ten days of infarction. Adding their cases to those of Levine and Brown they estimated that 65 per cent ruptured in the first week, 29 per cent in the second week, and more rarely at later stages. Analysis of the present series is in agreement with this conclusion.

\section{CONCLUSIONS}

The age of a cardiac infarct can be told from its histological appearances, with an accuracy within a range of 24 hours during the first week and of wider range at later stages.

The sequence of histological changes in the material examined agreed in general with that described by Mallory, White, and Salcedo-Salgar (1939).

Using the criteria described, the age of the infarct was estimated in nine cases of hæmopericardium. The ages ranged from 1 to 14 days, and in seven cases it was between $3 \frac{1}{2}$ and 10 days. In five cases the clinical history agreed with the ages assigned on histological grounds.

It is a pleasure to express my thanks to Professor Dorothy Russell for help in the preparation of this paper.

\section{REFERENCES}

Diaz-Rivera, R. S., and Miller, A. J. (1948). Amer. Heart J., 35, 126.

Edmondson, H. A., and Hoxie, H. J. (1942). Ibid., 24, 719.

Friedman, S., and White, P. D. (1944). Ann. intern. Med., 21, 778.

Harvey, William: Works, Translated by Sydenham Society, 1847, p. 127.

Jetter, W. W., and White, P. D. (1944) Ann. intern. Med., 21, 783.

Krumbhaar, E. B., and Crowell, C. (1925). Amer. J. med. Sci., 170, 828.

Levine, S. A., and Brown, C. L. (1928). Medicine (Baltimore), 8, 245.

Mallory, G. K., White, P. D., and Salcedo-Salgar, J. (1939). Amer. Heart J., 18, 647. 